\title{
Failure Investigation for Recently Constructed Road in Khartoum State
}

\author{
Omer G. Omer ${ }^{1}$, Ahmed M. Elsharief ${ }^{2}$ and Awad E. M. Mohamed ${ }^{2}$ \\ 1. Sudan Civil Aviation Authority, Khartoum 11111, Sudan \\ 2. Building and Road Research Institute, University of Khartoum, Khartoum 11111, Sudan
}

\begin{abstract}
This paper will visually and experimentally assess the level of deterioration of one of the new constructed ring road pavements in Khartoum State as well as to examine and identify the causes of the failed pavement. A series of field and laboratory exercises were carried out on the materials that were used in the construction of the designated pavement. Huttab, a natural gravelly material, was used in both subbase and base blend of this deteriorated pavement. The experimental tests consisted of two tasks: the first covered the study of the actual causes of pavement distress, whereas the second explored typical base material alternatives that satisfy base course needs. The tests involved basic tests and dynamic tests such as sieve, Atterberg limits, linear shrinkage, compaction, CBR (California bearing capacity), abrasion whereas the dynamic tests included $M_{R}$ (resilient modulus), and PD (permanent deformation). The routine tests showed that an improper base blend was used in the failed road that resulted in excessive rutting whereas in the second tests scenario the results showed that the proper base blend from the named materials gave high strength and stiffness values and low PD compared to the natural one. On the other hand, the pure crushed sample reported high $M_{R}$ values and the lowest PD compared to the base blend alternative.
\end{abstract}

Key words: Natural unbound material, blend, resilient modulus, gradation, permanent deformation.

\section{Introduction}

Khartoum, the capital of Sudan, is a tri-metropolis consisting of Khartoum, Khartoum North (Bahri), and Omdurman. These are naturally separated by the Nile River, but are linked by more than ten bridges crossing the Blue and White Niles. Khartoum has witnessed huge development in infrastructure, particularly in road construction. Some of this expansion is part of the national highway grid system. The aim of the considered ring-road is to by-pass the residential areas. It is important to note that the road construction industry in Sudan lacks construction codes, specifications, or local planning. Thus, specifications are borrowed from either AASHTO (American Association System of Highway and Transportation Office) or TRL (Transport Research Laboratory) of United Kingdom.

\footnotetext{
Corresponding author: Omer G. Omer, Ph.D., research field: construction and highway. E-mail: engurham1992@hotmail.com.
}

Flexible pavements are predominantly used to carry traffic loads. Natural materials from the available open quarries located around the capital are used for base and subbase layers. These natural quarried gravels are originally geological formations that are belonging to Nubian Sandstone [1]. The quality of available materials usually satisfies the requirements for subbase layers, but they rarely satisfy the strict requirements of unbound base course materials. For big projects, contractors usually mix the natural material with sand and/or crushed stone. The crushed stone are from a volcanic out cropping product that is found around Khartoum State. Overall, the performance of pavements carrying heavy traffic could be rated as poor. This poor performance may be attributed to the behavior of the natural unbound aggregates often adopted for use as base and subbase materials [2].

A wide range of materials can be used as unbound road bases, including crushed quarried rock and mechanically stabilized, modified, or naturally 
occurring gravels [3]. The stabilization process involves the addition of a stabilizing agent (natural sand, cement, and crushed stone) to the gravely materials to improve their strength and deformation characteristics. This paper highlights some technical assessments used in evaluating failure in pavements in Khartoum North.

Elyas [4] noted that DCP (dynamic cone penetrometer) was adopted as a non-destructive equipment to evaluate and estimate the material strength CBR (california bearing ratio) of the defective roads in Khartoum State, which were constructed using the available gravelly materials. According to Elyas [4], field and laboratory tests showed that the use of the DCP test to predict in-situ CBR was emphasized. DCP is most sensitive to clay content, moisture, gradation and density, concluding that heavy loads and weak subgrade are major causes of pavement distress. He recommended that special attention should be paid to subgrade strength, and advised the use of DCP to examine the mechanism governing permanent deformation within the flexible pavement layers, as well as to characterize and identify rutting caused by inadequate base/subbase and secondary compaction (from traffic). Elyas [4] also noted that most of the pavement failures in the studied area were due to the shoddy rainwater drainage system at the defected road section.

On the other hand, Margi [5] has lately adopted the PCI (pavement condition index) to evaluate the existing road pavements covering the 1,000 kilometres of the SNRN (Sudan national road network), and reported that the greater percentage of distress in all road sections is found to be in the lane/shoulder drop off. The average PCI of the entire road was found to be in fair condition (57\%), which means that more efforts should be made to maintain the roads or they will deteriorate. The outcome of his study appeared to indicate that the PCI method is a reliable approach for pavement evaluation.

Omer [6] evaluated the effect of different compaction methods on the gradation, strength, and physical properties of unbound gravelly soil materials obtained from quarries around Khartoum. The materials in the investigation were colluvium deposits —originally conglomerates belonging to Nubian Sandstone formation. Four materials were selected and sampled to cover different gradations (coarse, medium and fine gradations). The four unbound materials were tested in their natural state, and were subjected to three compaction methods in the laboratory, namely, impact, vibratory, and gyratory compaction. The gradation, plasticity and linear shrinkage were measured before and after compaction. The strength was assessed using the CBR test for the considered samples.

The impact compaction generally resulted in breakage of the coarse aggregates, reported remarkable increase in fines content for the four natural samples consequently resulted in high strength values for the four gravels compared to the other two compaction methods. This could be attributed to the better particles interlocking, enhanced by the produced broken pieces when the impact hammer was used.

The strength values given by the impact compaction, which is used as a standard compaction method for the CBR test in the laboratory, could lead to great over-estimation of the strength of field compacted samples (for the same placement conditions, i.e., density and water content).

\section{Literature Review}

Unbound granular materials are natural multi-phase materials comprising different sizes of aggregate particles, air voids, and water. Their mechanical characterization should ideally be based on the behaviour of the individual constituent elements and their interaction [7]. Kornel [8] noted that the term "unbound granular materials" could be expressed in almost any road pavement structure, when used as a highway base or as a base of low-volume roads. The term "bound materials" is used for a linear or nearly linear stress-strain relationship, whereas unbound 
relates to those are stress-dependent exhibits non-linear stress-strain behaviour [9]. Pavement unbound materials include many types of aggregates such as natural gravel, crushed gravel, and crushed rock [3].

The base course is a core element in the pavement structure, and is usually constructed using high quality road material. According to Kornel [8], the main function of the base is to reduce the vertical compressive stress induced by traffic in the sub-base and the subgrade to a level at which no unacceptable deformation will occur in these layers.

Dawson [10] described the base layer as the chief structural element of a pavement. It is the engineered heart, and the success or failure of the pavement's role depends, above all, on the base's performance — get the base right, and the essence of a successful pavement is assured.

Dawson et al. [11] noted that the base layer is the first pavement structural layer that takes the impact of the repeated trafficking load and should, therefore, be stiff enough to decrease the stress level on the subgrade soil:

- To a level which the soil can withstand without significant deformation;

- To provide adequate support for the surfacing as construction platform.

The base course in flexible pavements plays an important role in the overall performance of the pavement structure [2]. The main structural function of the base layer is to evenly distribute the stress generated by wheel loads acting on the HMA (hot mix asphalt) surface course to the subgrade via the underneath sub base. As such, the stresses transmitted to the subgrade will not result in excessive deformation or displacement of the foundation soil [2].

The gradation of UGMs (unbound granular materials) greatly influences the resilient response of the UGMs, and it is one of the important material variables. Well-graded material can achieve higher densities and lead to higher stiffness [12]. Lekarp et al. [12] reported that one of the factors affecting resilient response of granular materials is the fine content; the stiffness reversely decreases with the increase of fine content. Stiffness is fines content dependent. Densely graded materials usually achieve the highest resilient modulus values as the fine content is below $9 \%$, but decreases gradually as the fine content exceeds that value [13]. Hicks and Monismith [14], Allen [15], Allen and Thompson [16], Thom and Brown [17], Barksdale and Itani [18], Stolle et al. [19] and Kim [20] all noted that crushed aggregates having angular to sub-angular shaped particles that provide better load spreading and higher resilient moduli than uncrushed gravels with round surfaces.

Arnold et al. [21] assessed and commented that 30\% to $70 \%$ of surface rutting is attributed to the unbound granular material layers. They added that the available natural materials can, however, be assessed for their suitability for use in a pavement by considering performance criteria such as resistance to permanent deformation and degradation instead of relying on compliance with inflexible specifications.

From local studies, Ismail [22] investigated the engineering properties of five typical natural gravels provided from different open quarries in North Kordofan State (west of Khartoum State). The study showed that the five selected gravel samples failed to satisfy the base requirements BS (British Standards) and AASHTO. Mechanical stabilization trials were then carried out to improve them by adding different percentages of clean natural coarse sand $(10 \%, 15 \%$, and $17 \%)$. The test results indicated that $17 \%$ added sand reduced the plasticity and improved gradation, allowing for the measured strength to satisfy the base course requirements.

Pavement performance depends on proper design of both the asphalt mix and pavement structure. If both elements are subpar, this will result in failure of the pavement [23].

Nada [24] investigated and reported that recently buildings as well as streets in old Omdurman City were noted to deteriorate; these deteriorations were 
attributed to the presence of perched water at foundation level, accumulated on impermeable strata of mudstone at shallow depths. She also noted this type of failure in the main street of Al-Zaeem Al-Azahari that links Omdurman to Khartoum North, Plate 1.

On the other hand, Zumrawi [25] reported that the aforementioned roads Alazhari and Alarda roads suffered from severe distresses of potholes, rutting, and heavy depressions. The causes of these failures may be due to improper design, excessive loads and poor drainage, leading to poor subgrade conditions. These reasons were supported by the experimental investigation performed by University of Khartoum's Consultancy Corporation.

\section{Case Study}

The ring road links two national highways passing within Khartoum North premises (Al-Gaili-Alhaj Yousif). It was designed to support heavy traffic, and was planned to transfer traffic from the east and middle of Sudan without crossing Khartoum city. The construction material recommended for subbase layers was the natural unbound gravelly material from the adjacent open quarries such as Huttab or Al-Silait, as well as a blend of well graded dense pure crushed stone for base course from one of scattered computerized crushing plants in Khartoum State. But for some unexplained reason (that is perhaps financial), the road was not executed as designed, particularly the well-graded dense pure crushed stone base layer. It was replaced by natural gravel from Huttab blended with plant over-sized crushed rock product ( $25 \mathrm{~mm}$ to $75 \mathrm{~mm}$ ) aiming at restructuring and strengthening the mentioned natural material, Plate 2, Plate 3. Two years after it has been opened for traffic, the road shows severe rutting that has propagated along the west lane. This could be attributed to the heavy loaded trucks, tippers, and loaded fuel tankers. Plate 4 shows $50 \mathrm{~mm}$ rutting (permanent deformation).

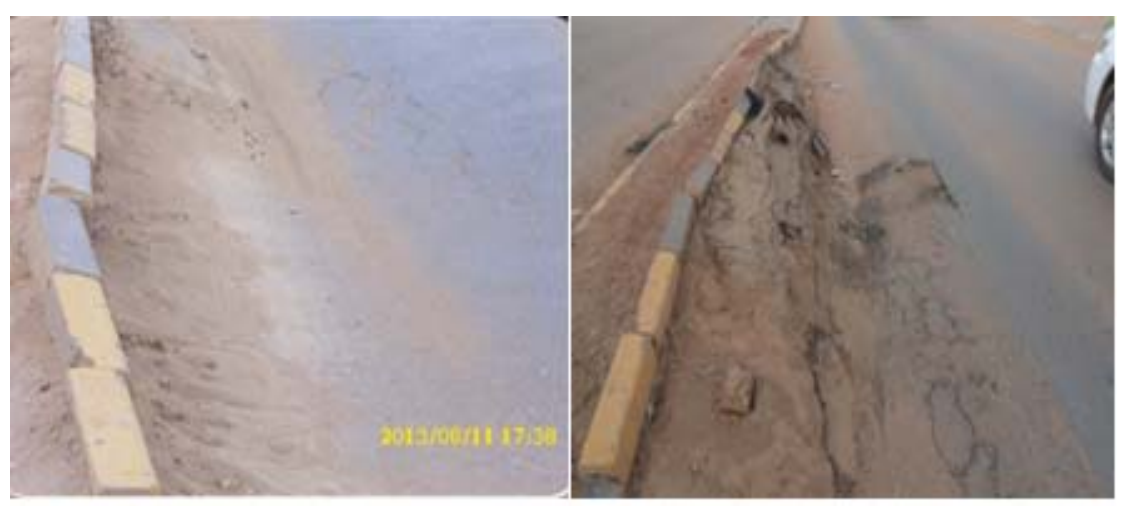

Plate. 1 Excessive deterioration of Al-Azahari street in Omdurman city [21].

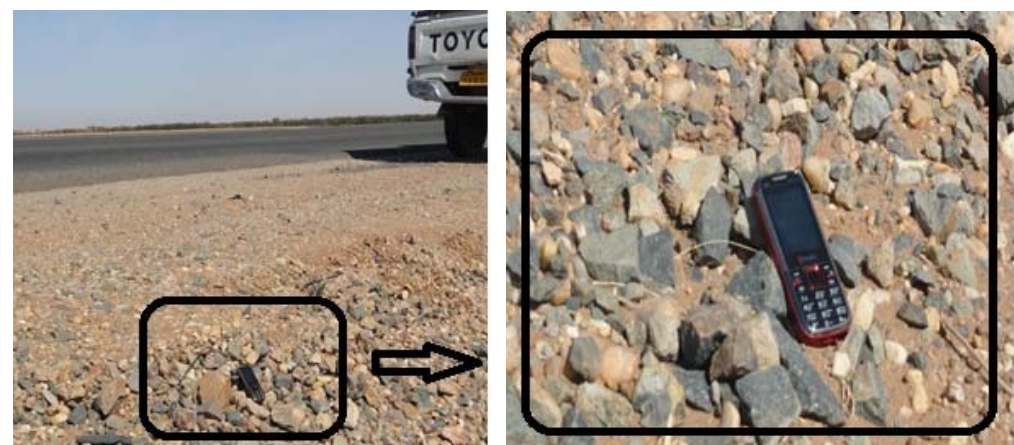

Plate. 2 The improper base course blend of the rutted pavement in the ring road (Khartoum-North). 

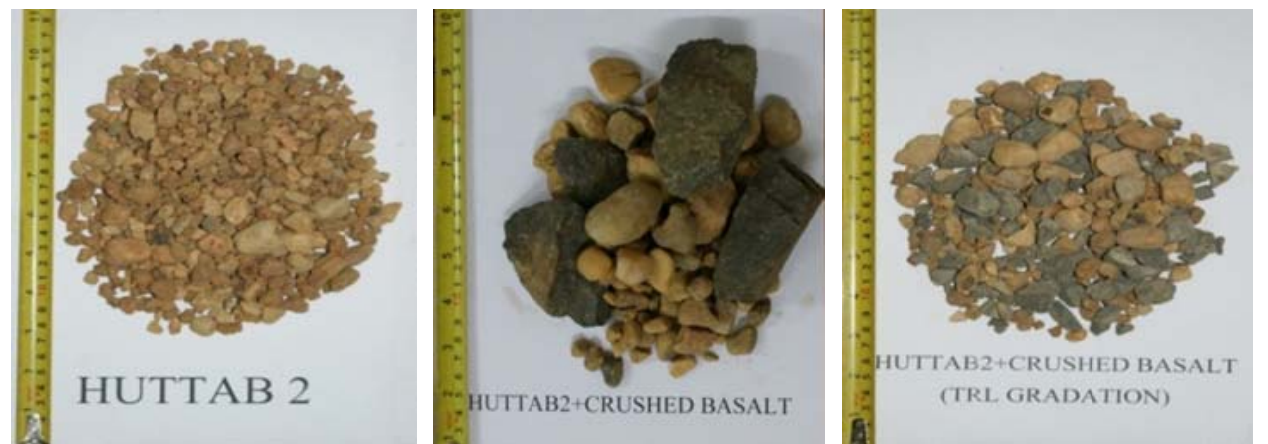

Plate. 3 The sieved coarse aggregate (passing 20 \& retained on sieve 4.75mm) for Huttab 2 natural, randomly blended \& perfectly blended.
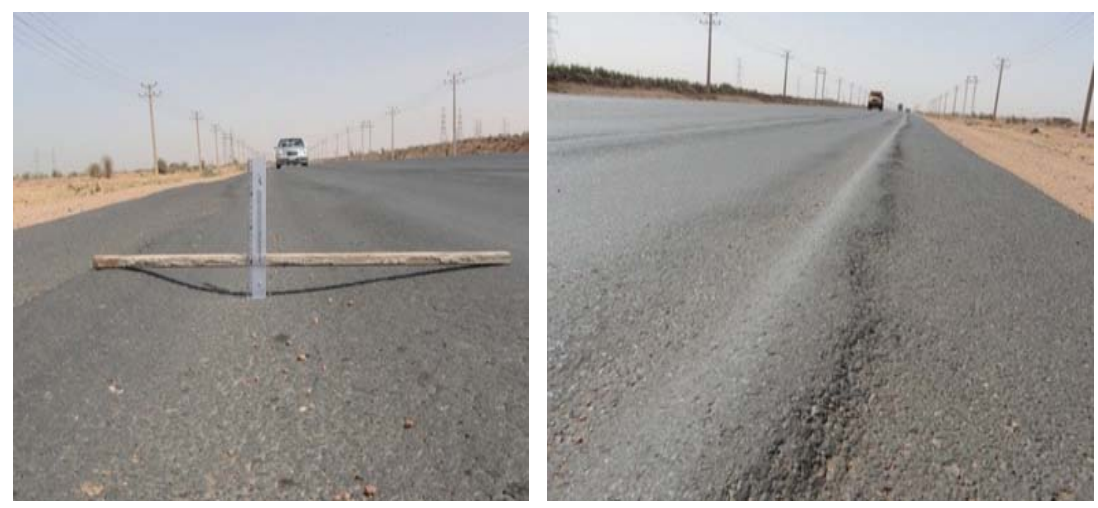

Plate. 4 The excessive rutting (50 $\mathrm{mm})$ occurred in the ring road El-Gaili-Haj Yousif (west lane).

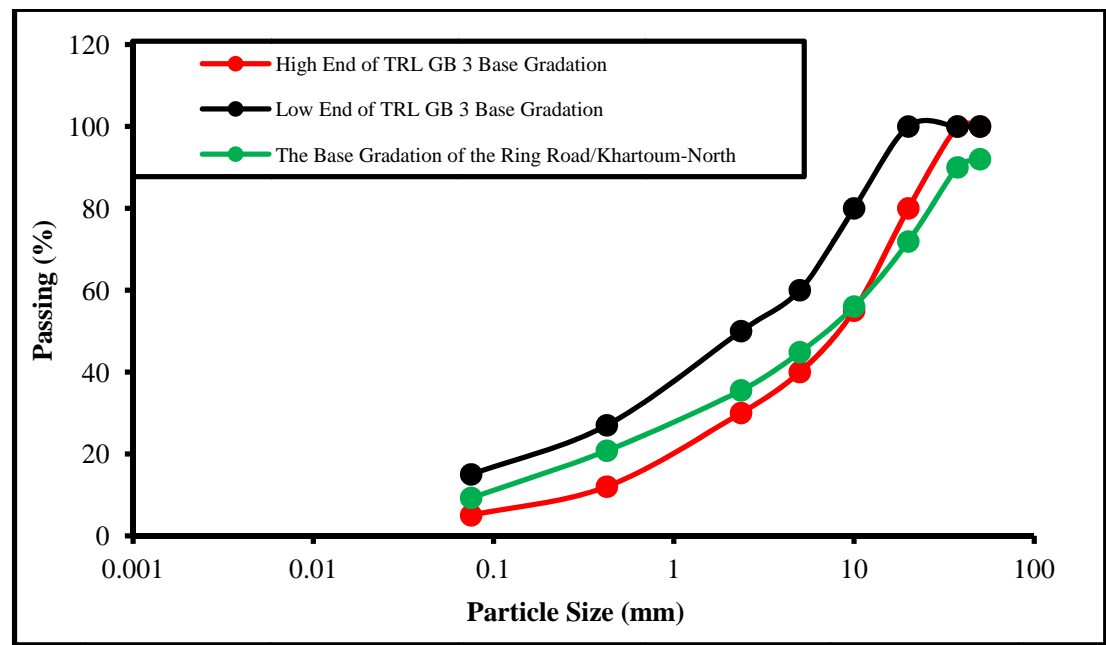

Fig. 1 Grain size distribution of the existing rutted base course (ring road in Khartoum-North).

Three cores were dug at different locations along the rutted trenched lane down to $200 \mathrm{~mm}$ in the existing subgrade using a sew-cutter and jackhammer. The reported thicknesses of the typical distressed pavement is as follows: $50 \mathrm{~mm}$ hot-mix asphalt, $200 \mathrm{~mm}$ base layer, and a variable thickness for subbase course that ranges from $300 \mathrm{~mm}$ to $400 \mathrm{~mm}$. Representative samples for base, subbase materials were immediately packed in plastic bags and transported to the laboratory. From the post-testing results of the existing base blend, it appeared that the used blend gradation and engineering properties were not satisfying the required base specifications as observed in Plate 2 and Fig. 1, where Fig. 1 shows the particle size distribution of rutted base course.

The primary objective of this specified case study is 
to technically assess the reasons that might cause the observed rutting in this ring road, as well as to determine the most suitable laboratory practices for evaluating the strength, stiffness, and deformation resistance of the used unbound materials in road construction.

The reported failure in Plate 4 might be a base failure for that; an experimental investigation is proposed to concentrate this assessment on the used base materials, which are (1) Huttab natural unbound gravelly material and (2) three manufactured sizes of basaltic crushed stone (19-12, 12-5, 5-0 mm) as blending agent.

\section{Materials and Test Methods}

The main objective of this investigation is to review the deterioration causes of the existing pavement in the west lane of the Ring Road (Al-Gaili-Alhaj Yousif), as well as to ascertain the adequate base blend alternative for the designated natural gravel used in the studied area. The engineering properties such as strength, stiffness and deformation resistance for this suggested proper base blend were also studied.

The remaining stockpiled natural gravel from Huttab that was previously used in constructing the distress sections are still scattered along the road. Representative Huttab gravel were collected from the stockpiled points, batched in plastic bags and then transported to the laboratory. On the other hand, three different sizes from basaltic crushed stone (19-12, 12-5, 5-0 mm) as blending agent were provided from a mounted crushing plant in Jebel Touryia in Southwest Khartoum. As previously mentioned, representative samples of typical constructed materials from the three cored points in the rutted sector were also sent to the laboratory for post-testing.

Khartoum State is considered part of a depression filled with formations of different ages. It is located adjacent to the Central Sudan rift basin, also known as the Khartoum basin. Huttab natural gravel is one of these various aged formations, which are colluvial deposits that were originally conglomerates belonging to the Nubian Sandstone Formation. This Nubian Sandstone is a formation that has been deposited by braided streams under semi-dry tropical climate [1].

Huttab natural gravel is commonly used by the road contractors as base and subbase material. Three samples were prepared and chosen for this assessment: Huttab natural unbound gravel; Huttab natural unbound gravel blended with crushed basaltic stone that satisfies TRL base gradation GB3 $\{(54 \%$ Huttab natural $+11 \%$ $(19-12 \mathrm{~mm})+10 \%(12-5 \mathrm{~mm})+25 \%(5-0 \mathrm{~mm})\}$; and pure dense well graded blend from different sizes of crushed basaltic stone according to TRL base gradation GB 1 (as the extreme end of base specifications).

The experimental program for this assessment comprised routine laboratory tests to study their engineering properties. These included sieve tests, Atterberg limits, linear shrinkage, compaction, and CBR tests. Advanced tests such as $M_{R}$ (resilient modulus)and PD (permanent deformation) were also carried out for the considered assessment to evaluate the strength, stiffness, and deformation resistance of the materials in question. All laboratory tests were carried out according to the BS and AASHTO.

The CBR is one of the methods upon which the structural design was based, i.e., it is a common method used to characterize the granular materials of the various road layers (base, subbase and subgrade). Dynamic triaxial load apparatus appears to be the modern equipment to adequately characterize all pavement materials, and as such was used for resilient modulus and permanent deformation tests.

When actual field conditions for these typical natural gravels and their blends such as Huttab were simulated, the vibrated specimen for resilient modulus was less affected when compared to the CBR specimen (moulded using impact hammer). The impact hammer is a key tool that commonly used to mould CBR specimens. It uses to break-down the coarse particles, improves material gradation, PI, and the other engineering properties consequently enhances the strength of the produced degraded material and that 
could lead to over-estimated results whereas resilient modulus and permanent deformation provide accurate characterization for all pavement materials.

\section{Tests Results}

A summary of results for the tests that were carried out in this investigation is displayed below:

Fig. 1 shows the grain size distribution of the existing rutted base course (ring road in Khartoum North). The coarse aggregates that passed through the $20 \mathrm{~mm}$ sieve and were retained on the $4.75 \mathrm{~mm}$ sieve for Huttab natural, randomly blended, and perfectly blended are depicted in Plate 4.

Fig. 2 presents the grain size distribution plots for the existing rutted base course (ring road in Khartoum-North) and Huttab 2 natural gravel compared to TRL GB 3 base gradation bands.

Fig. 3 displays the grain size distribution for Huttab natural and properly blended with crushed stone compared to TRL GB 3 base gradation. Compaction test results for the three samples are given in Table 1.

The gradation of the pure crushed basaltic stone blend $\{50.3 \%(19-12 \mathrm{~mm})+22.4 \%(12-5 \mathrm{~mm})+27.3 \%$ (5-0 mm) \} compared to TRL GB1 base gradation is given in Fig. 4. $M_{R}$ test results for Huttab 2 natural, blended with crushed stone and pure crushed stone are shown in Fig. 5.

Fig. 6 gives the engineering properties for Huttab 2 natural, Huttab 2 blended with crushed stone, and pure crushed stone. Table 2 gives the permanent deformation results for Huttab 2 natural, Huttab 2 blend and pure crushed stone blend.

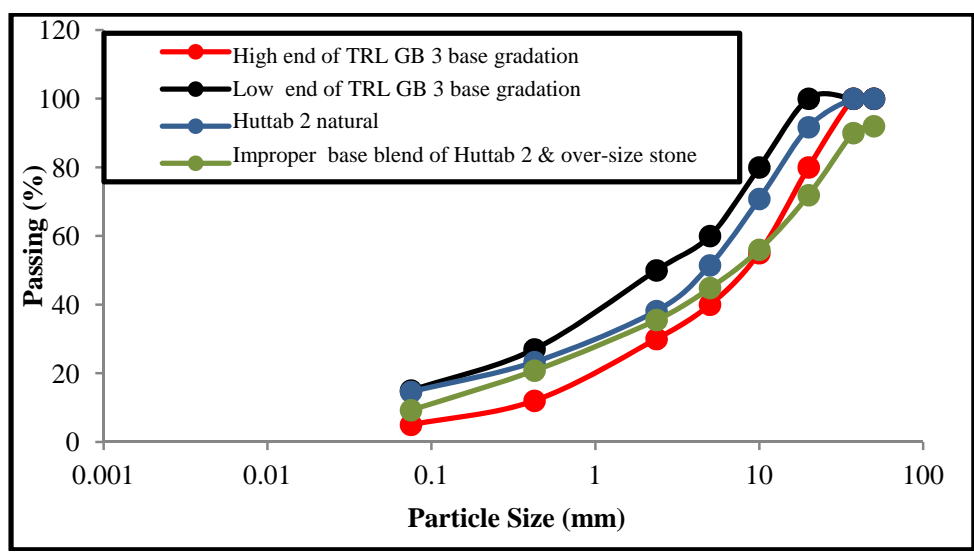

Fig. 2 Grain size distribution plots for the existing rutted base course (ring-road in Khartoum-North) and Huttab 2 natural gravel compared to TRL GB 3 base gradations.

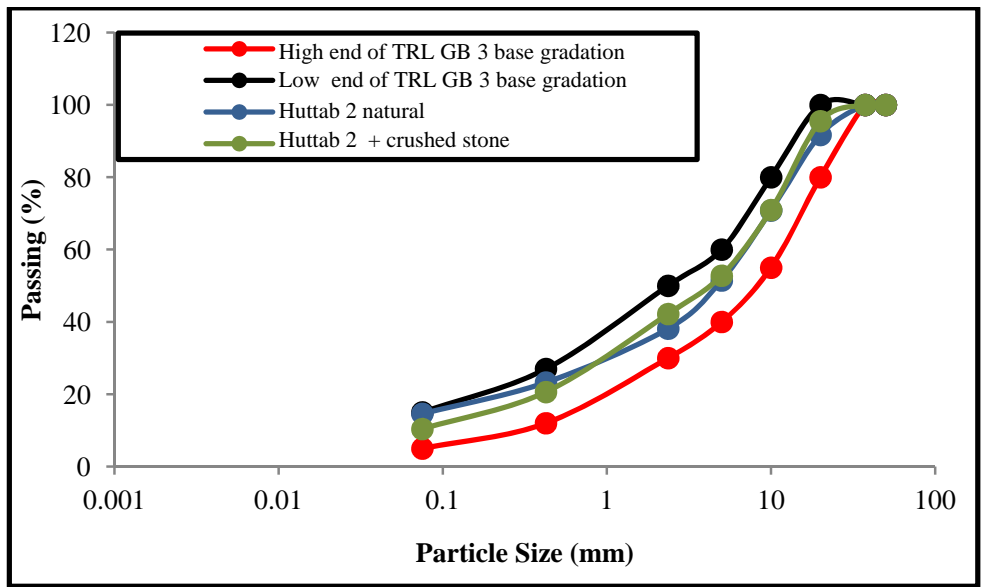

Fig. 3 Grain size distribution for Huttab 2 natural, and blended compared to TRL GB 3 base gradation. 
Table 1 Compaction Test Results for the Three Samples.

\begin{tabular}{lll}
\hline Type of sample material & Optimum moisture content $(\%)$ & Maximum dry density $\left(\mathrm{gm} / \mathrm{cm}^{3}\right)$ \\
\hline Huttab 2 natural gravel & 7.25 & 2.19 \\
Huttab 2 blended & 5.6 & 2.224 \\
Pure crushed stone & 2.89 & 2.24 \\
\hline
\end{tabular}

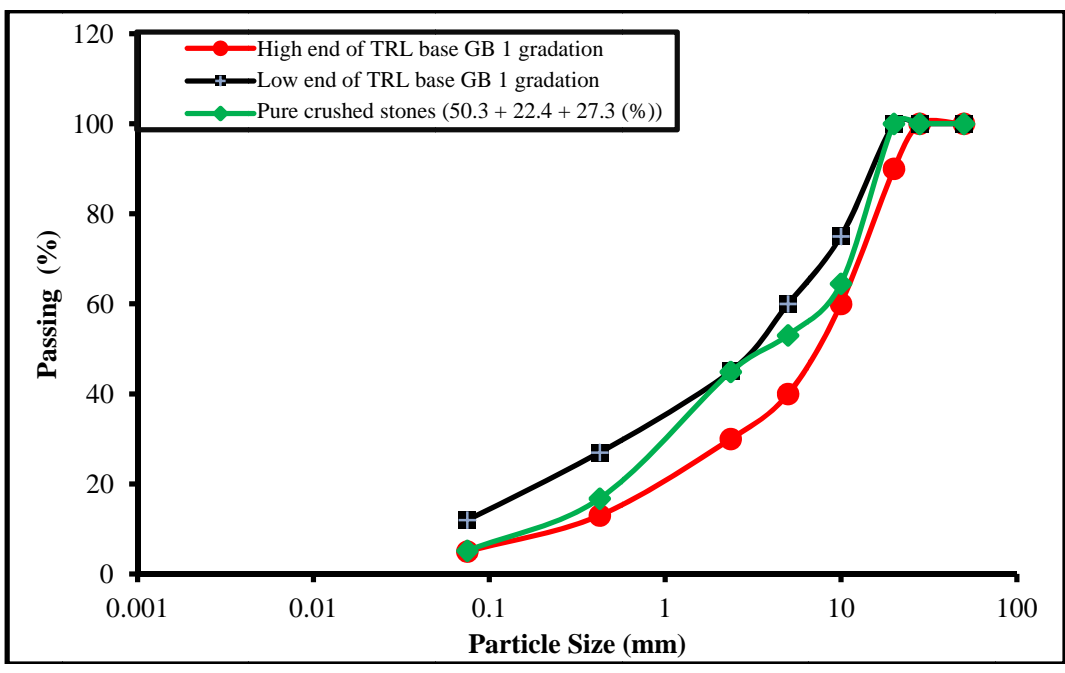

Fig. 4 Gradation for the pure crushed basaltic stone compared to TRL GB 1 base gradation.

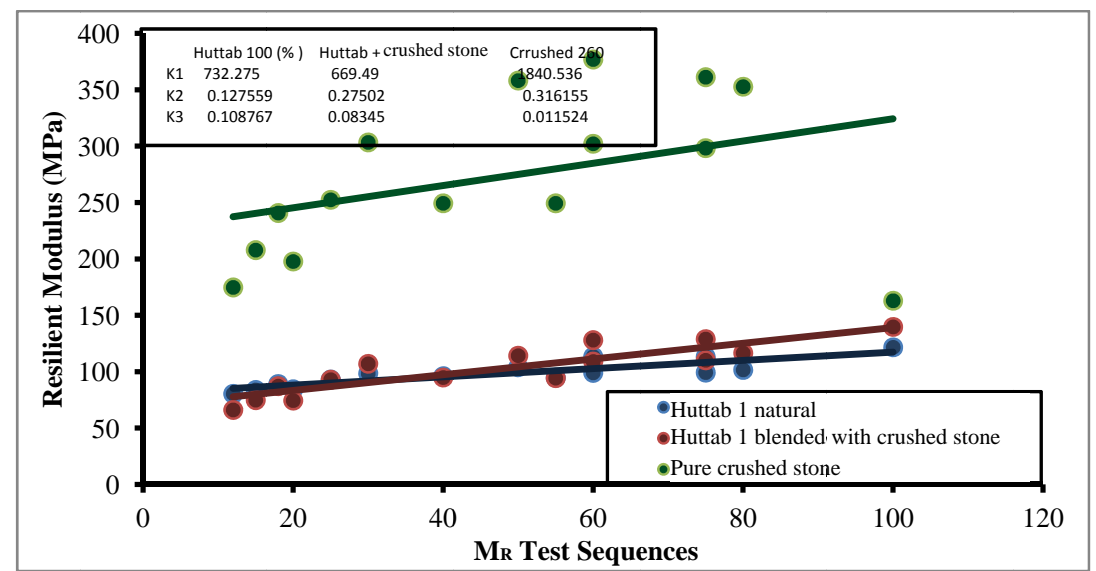

Fig. 5 Resilient modulus tests results for Huttab 2 natural, blended \& pure crushed stone.

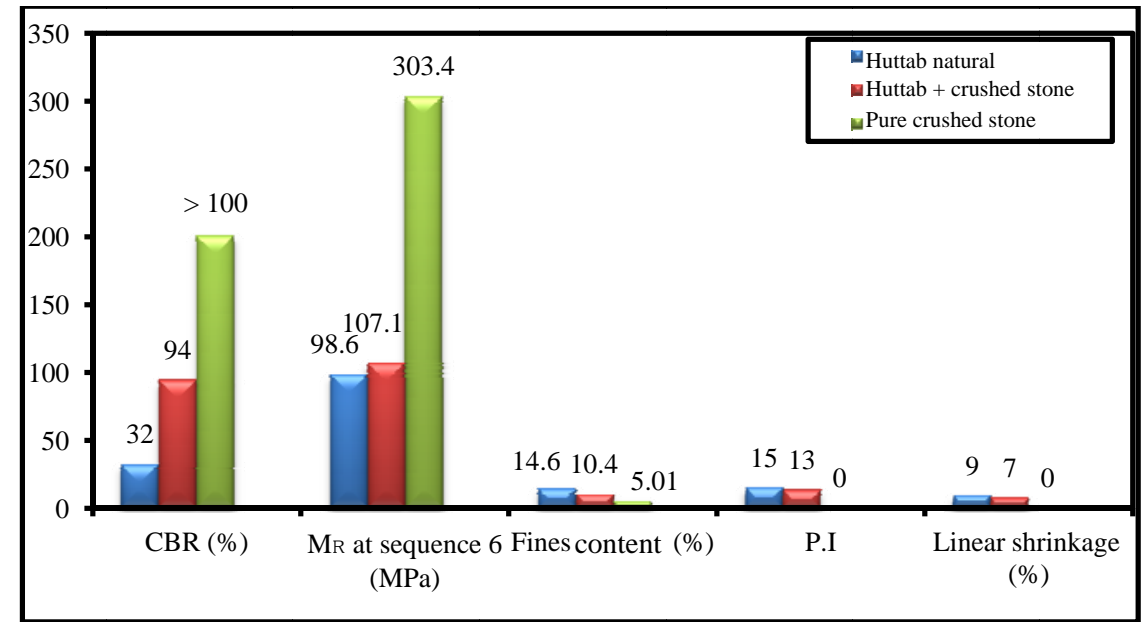

Fig. 6 The engineering properties for Huttab 2 natural, blended \& pure crushed stone. 
Table 2 PD test results for Huttab 2 natural, Huttab 2 blend (TRL GB 3).

\begin{tabular}{ll}
\hline Type of material & Permanent deformation (mm) \\
\hline Huttab 2 natural gravel & 0.091 \\
Huttab 2 blend (with crushed stone) TRL GB 3 & 0.058 \\
Pure crushed stone blend, TRL GB 1 & 0.00146 \\
\hline
\end{tabular}

\section{Results Analysis and Discussions}

The main objective of this study is to explore the causes that led the ring road flexible pavement (Al-Gaili-Alhaj Yousif) to rut, as well as to adopt an adequate base blend alternative for the designated natural gravel that was used in the studied pavement. The final objective is to study engineering properties such as strength, stiffness and deformation resistance for this suggested proper base blend.

Based on the site observation, the construction companies in the studied sector have stabilized Huttab 2 natural gravel with a crushed stone agent that contains almost 30\% over-sized crushed stone boulders (75-25 $\mathrm{mm}$ ) as shown in Plates 2 and 3, Figs. 1 and 2. It was found difficult and impractical to reconstitute this blend in the laboratory for testing due to the presence of large size particles, which are dominant in the blending agent as mentioned above. Moulding of any coarse grained material for compaction, CBR, resilient modulus and permanent deformation tests require $19.05 \mathrm{~mm}$ as a nominal maximum particle size $(150 \mathrm{~mm}$ is the mould inner diameter).

Plate 4 shows the excessive rutted and trenched lane along the investigated ring road sector; the measured permanent deformation is $50 \mathrm{~mm}$. The post-tests results of the existing failed pavement proved that this deterioration is associated to base failure and that could be attributed to the gradation as well as non-uniformity of the two mixed materials of the used base blend, as well as engineering properties which were unsatisfactory to base material specifications. It is a fact that Huttab 2 natural gravel was randomly blended with crushing plant over-sized rock product ( $25 \mathrm{~mm}$ to 75 $\mathrm{mm}$ ) as shown in Plates 2 and 3, Figs. 1 and 2. The measured existing moisture of the constructed base blend was $0.688 \%$. Therefore, the deteriorated base course was definitely compacted at moisture less than the OMC (optimum moisture content) of the used blend (dry of optimum). In fact, it can be noted that this improper exercise zoned in three reasons-insufficient design and non-homogenous materials used, poor construction level, and absence of direct supervision.

Based on the sieve analysis tests of Huttab 2 natural gravel, Fig. 2, the retained percentage coarse particles on the $37.5 \mathrm{~mm}$ sieve is 0 (100\% passing), whereas the amount retained on the coarser sieve $(20 \mathrm{~mm})$ is $8.29 \%$ (91.71\% passing). Therefore, this size is the nominal maximum particle size; consequently, the type of base gradation must be governed by this size (TRL). However, the used stabilizer of crushed stone has reported sizes greater than $20 \mathrm{~mm}$ (over-sized particles), thus producing improper base gradation as shown in Fig. 2.

Grain size distribution test results of the three investigated samples are presented in the following figures: Fig. 3 plots the gradation for Huttab 2 natural and Huttab 2 blend compared to TRL GB 3 base gradation. It is observed that the Huttab 2 natural gradation curve falls within the TRL GB 3 gradation envelope, but does not properly coincide with the middle range of TRL gradation. On the other hand, the Huttab 2 blend shifted the structured mix and fit well with the middle range of TRL GB 3 base gradation. Fig. 4 shows the gradation curve for the pure crushed basaltic stone sample $\{50.3 \%(19-12 \mathrm{~mm})+22.4 \%(12-5 \mathrm{~mm})$ $+27.3 \%(5-0 \mathrm{~mm})\}$ compared to TRL GB 1 base gradation, which fit the required gradation.

The compaction test results for the three considered samples are given in Table 1. It is observed that the Huttab 2 blend reported better dry unit value compared to that obtained by Huttab 2 natural. The resilient modulus test results are displayed in Fig. 5 for the three samples. Considerably improved stiffness is observed for Huttab 2 natural when blended with the crushed 
stone. An increase of $11 \%$ of resilient modulus values is experienced when compared to Huttab 2 natural. The well dense pure crushed stone gives the highest resilient modulus values (almost twice that resulted by the blended sample), mainly due to proper particles interlocking that reported in high stiffness values $\left(M_{R}\right)$. The resilient modulus value at sequence 6 is used as a benchmark.

The increase in stiffness reported by resilient modulus will strongly enhance the performance of base blend under repeated traffic rather than the overestimated CBR (moulded by impact hammer) for these gravelly materials that automatically orient to inadequate pavement structural design.

The engineering properties for the three samples in question are given in Fig. 6. The measured strength and stiffness (CBR\% and MRseq.6) experienced remarkable improvement for Huttab 2 when blended with the crushed stone and reversely the PI, linear shrinkage and fines content percentage decreased. The well dense pure crushed stone measured the highest strength and stiffness values (CBR\% \& MRseq.6). Table 2 gives the permanent deformation test results for the three samples in question. It is observed that the Huttab 2 blend measured permanent deformation value smaller than that obtained by Huttab 2 natural; this is attributed to the adequate blending, whereas the pure crushed stone reported low permanent deformation values among the three samples. This is due to proper interlocking of the sample cube-shaped particles.

It is crucial to conduct an intensive geotechnical investigation along the proposed road alignment and then followed by proper comprehensive field and laboratory tests for all proposed pavement materials prior to construction.

Although resilient modulus and permanent deformation tests are expensive and time consuming, their obtained parameters are highly important for mechanistic-empirical design for these typical road materials basically to ensure long lasting pavement performance.

\section{Conclusions}

This paper focused on the adopted testing program used in this current study, which was oriented towards assessing and identifying the reasons that caused the pavement distress of the given ring road in Khartoum State. The selected materials for the study are the same road materials that were typically used in the construction of the deteriorated road; Huttab 2 gravel and the basaltic crushed stone.

The actual field rutting was directly measured. The improper base blend was initially subjected only to sieve tests, whereas the routine tests as well as resilient modulus and permanent deformation tests were carried out on Huttab 2 natural, Huttab 2 proper base blend, and crushed stone sample. Their results for engineering properties, strength, stiffness and deformation resistance were comparatively evaluated.

The outcome is summarized in the following:

The first impression from the site visit observation is that the severe trenched west lane might have been caused by the movements of heavily loaded truck-trailers, tippers, as well as loaded fuel tankers. The damage could also be attributed to insufficient implementation process, inadequate design or improper pavement materials used.

Post-sieve testing results for the cored base samples proved that the blend gradation that was used did not satisfy the requirements of TRL GB 3 base gradation.

The non-homogeneity of gradation of the base blend caused the entire lane of the considered sector in the studied road to rut due to excessive base failure.

It was found that the proper blending process for Huttab natural with the crushed stone improved the gradation and fit the TRL GB 3 base gradation, while the adopted blending percentages for pure crushed sample fit well with the middle range of the TRL GB 1 base gradation.

In general, the well graded dense pure crushed stone sample resulted in high strength and stiffness values (CBR\% and MRseq.6) compared to the other two remaining samples, whereas Huttab blend gave higher 
strength, stiffness values (CBR\% and MRseq.6) than that reported by Huttab natural while satisfying the base strength requirement.

Huttab blend measured a remarkable decrease in plasticity index, fines content and linear shrinkage compared to Huttab natural gravel.

It was observed that the Huttab blend measured a permanent deformation value smaller than that obtained by Huttab natural; this is attributed to adequate blending, whereas the pure crushed stone reported low permanent deformation values compared to the two other samples.

Proper geotechnical investigation and land survey for any proposed project area as well as the adopted pavement materials are of extremely importance prior to construction.

Although resilient modulus and permanent deformation tests are expensive and time consuming, their obtained parameters are highly significant to the mechanistic-empirical design for these typical road materials to ensure long lasting pavement performance.

To ensure good pavement performance, adequate design, quality materials as well as perfect pavement implementation and above all direct supervision are needed.

Get the base right and the essence of a successful pavement is assured [8].

\section{References}

[1] A.J. Whiteman, The Geology of Sudan Republic, Clarendon Press: Oxford University Press, Oxford, 1971, pp. 63-72.

[2] O.G. Omer, M.A. Elshareif, A.M. Mohamed, Improvement of unbound aggregates in Khartoum State, in: Proceedings of the 15th African Regional Conference in Geotechnical Engineer, Maputo-Mouzambique, 2011, pp. 217-223.

[3] A guide to the structural design of bitumen-surfaced roads in tropical and sub-tropical countries, overseas centre, TRL (1991) 1-31.

[4] M.T.M. Elyas, Use of DCP for design/structural evaluation of roads and airfields, M.Sc. Thesis, University of Khartoum, Khartoum, Sudan, 1991 .

[5] K.M. Margi, Adaptation of (HDM4) and (PCI) for prioritizing pavement maintenance of Sudan paved roads network, Ph.D. Thesis, University of Khartoum,
Khartoum, Sudan, 2010.

[6] G.O. Omer, Evaluation of natural aggregates and crushed stone as base material, Ph.D. Thesis, University of Khartoum, Khartoum, Sudan, 2013.

[7] A.O. Alex, Characterization of Unbound Granular Layers in Flexible Pavements, Research report ICAR (International Center for Aggregates Research)—502-3, Texas Transportation Institute, Texas College Station, Texas A\&M University, Texas, USA, 2001.

[8] K. Almassy, Examination of mechanical properties of unbound bases, Periodica Polytechnica Ser. Civ. Eng. 46 (1) (2002) 53-69.

[9] M. Popic, T. Susdn, The Effect of seasonal variation on the resilient modulus of unbound materials, in: Proceedings of Annual Conference of Transportation Association of Canada, Calgary, Alberta, 2005, pp. 3-5.

[10] A.R. Dawson, The unbound aggregate pavement base, in: Proceedings of the ICAR 3rd Annual Symposium, 1995.

[11] A.R. Dawson, L. Cheung, The effects of particle and mix characteristics on the performance of some granular materials, Transportation Research Record: Journal of the Transportation Research Board (1787) (2002) 90-98.

[12] F. Lekarp, U. Isacsson, A. Dawson, State of the art. I: resilient response of unbound aggregates, Journal of Transportation and Engineering 126 (1) (2000) 66-75.

[13] B.A. Magnusdottir, S. Erlingsson, Repeated load tri-axial testing for quantity assessment of unbound granular base course materials, in: Proceedings from the 9th Nordic Aggregate Research Conference, Reykjavik, Iceland, 2002

[14] R.G. Hicks, C. L. Monismith, Factors Influencing the Resilient Response od Granular Materials, Record No. 345, Highway Research Board, Washington, DC, 1971, pp. 15-31.

[15] J. Allen, The effect of non-constant lateral pressures of the resilient response of granular materials, Ph.D. Thesis, Department of Civil and Environmental Engineering, University of Illinois at Urbana-Champaign, Urbana, Illinois, 1973.

[16] J.J. Allen, M.R. Thompson, Resilient Response of Granular Materials Subjected to Time Dependent Lateral Stresses, Transportation Research Board, Washington, DC, 1974, pp. 1-13.

[17] N.H. Thom, S.F. Brown, Effect of Moisture on the Structural Performance of a Crushed-Limestone Road Base, National Research Council, Washington, DC, 1987, pp. 50-56.

[18] R.D. Barksdale, S.Y. Itani, Influence of Aggregate Shape on Base Behaviour, National Research Council, Washington, DC, 1989, pp. 173-182.

[19] D.F.L. Stolle, P. Guo, Y. Liu, Resilient Modulus 
Properties of Typical Granular Base Materials of Ontario, Sea to Sky Geotechnique, Department of Civil Engineering Mc Master University, Hamilton, Ontario, Canada, 2006, pp. 236-243.

[20] S.H. Kim, Determination of aggregate physical properties and its effect on cross-anisotropic behaviour of unbound aggregate materials, Ph.D. Thesis, Texas A\&M University, 2004.

[21] G.K. Arnold, A.R. Dawson, D. Hughes, D. Robinson, Serviceability design of granular pavement materials, in: Proceedings of the 6th International Conference on the Bearing Capacity of Roads and Airfields, Lisbon, Portugal, 2002, pp. 957-966.
[22] M.D. Ismail, Evaluation and characterization of granular soils as pavement materials in North Kordofan State, M.Sc. Thesis, Kararay University, Sudan, 2013.

[23] G.A. Ali, New technology in highway and pavement industry, in: Seminar organized by Ministry of Planning \& Public Utilities and CETS, Khartoum, Sudan, August, 2003.

[24] N.A.E. Mubarak, Effect of rising ground water on engineering structure at some areas in omdurman town, M.Sc. Thesis, University of Khartoum, Sudan, 2011.

[25] M.M.E. Zumrawi, Pavement design for roads on expansive clay subgrades, University of Khartoum Engineering Journal 3 (1) (2013) 51-57. 